\title{
A Teoria das Restrições: Estudo de Caso em uma Indústria de Couros do Estado de Santa Catarina
}

\author{
Theory of Constraints: A Case Study in a Leather Factory in Santa Catarina State
}

\section{Fernanda da Silva Fernandes}

Mestre em Ciências Contábeis na Universidade Federal do Rio de Janeiro

Endereço: Av. Pasteur, 250 - FACC - Praia Vermelha

CEP: 22290-240 - Rio de Janeiro - RJ

E-mail: ffernandes005@hotmail.com

Telefone: (21) 3873-5119

\section{Luciana de Jesus Delfino Fernandes}

Mestre em Ciências Contábeis na Universidade Federal do Rio de Janeiro Endereço: Av. Pasteur, 250 - FACC - Praia Vermelha

CEP: 22290-240 - Rio de Janeiro - RJ

E-mail: 1delfino@click21.com.br

Telefone: (21) 3873-5119

\section{Renata Gonçalves Pereira}

Mestre em Ciências Contábeis pela Universidade Federal do Rio de Janeiro Endereço: Av. Pasteur, 250 - FACC - Praia Vermelha

CEP: 22290-240 - Rio de Janeiro - RJ

E-mail: renatagoncalves12@hotmail.com

Telefone: (21) 3873-5119

\section{Samuel Cogan}

Doutor em Engenharia de Produção na Universidade Federal do Rio de Janeiro (Coppe)

Professor do Mestrado em Ciências Contábeis da Universidade Federal do Rio de Janeiro

Endereço: Rua General Venâncio Flores 226 apto. 303, Bairro Leblon

CEP: 22441-090 - Rio de Janeiro/RJ - Brasil

E-mail: scogan@uol.com.br

Telefone: (21) 2294-9137

Artigo recebido em junho de 2008. Passou por uma avaliação double blind review em outubro de 2008. Aceito em abril de 2009 pela Editora Científica Sandra Rolim Ensslin. . 


\title{
Resumo
}

Este estudo explora a aplicação dos fundamentos da Teoria das Restrições (TOC) em uma indústria de couros, caracterizada como curtume integrado. O objetivo foi evidenciar de forma empírica a aplicação da teoria para a tomada de decisão, relacionada à gestão das restrições e promoção de melhorias na produtividade. São analisadas neste estudo as principais restrições do processo produtivo desta empresa e a aplicação prática da $T O C$, levantadas por entrevista e demonstrativos contábeis. O resultado demonstra que a aplicação dos princípios da $T O C$ permite o aprimoramento e a agilização do processo de tomada de decisões, focado em suas metas: lucro e crescimento.

Palavras-chave: Teoria das Restrições, Contabilidade de Custos, Contabilidade Gerencial.

\begin{abstract}
This study investigates the application of the tenets of the Theory of Constraints (TOC) in a leather factory with an integrated tannery. The purpose was to empirically demonstrate the application of this theory to decision-making related to constraint management and productivity improvement. This study analyzes the main constraints in the productive process of the company being investigated, as well as the implementation of $T O C$, relying on information gathered through interviews and accounting statements. The results show that by applying the $T O C$ principles, it is possible to improve and expedite the decision-making process, focusing on specific goals: profit and growth.
\end{abstract}

Key words: Theory of Constraints, Cost Accounting, Management Accounting.

\section{Introdução}

A Teoria das Restrições (Theory of Constraints - TOC) foi criada pelo físico israelense Eliyahu Moshe Goldratt. A disseminação do conhecimento dessa técnica, filosofia, teoria, deu-se especialmente pelo livro "A Meta" (The Goal), escrito não de forma acadêmica ou de um manual prático, mas um romance no qual eram apresentados princípios ao longo de uma situação empresarial fictícia.

Esse tema tem suscitado interesse de pesquisadores que buscam evidenciar formas de aplicação dessa teoria no contexto brasileiro, realizados por vezes com o uso de simulações teóricas (MARTINS, 2002; SANTOS, 2006; SABBADINI, 2007; CASTRO, 2008).

O objetivo do presente estudo é evidenciar de forma empírica a aplicação da Teoria das Restrições no processo de tomada de decisão em uma indústria, bem como identificar os possíveis benefícios advindos da aplicação dos pressupostos dessa teoria. Apesar de ter sido desenvolvida há quase duas décadas, e desde então terem sido realizados muitos estudos sobre a TOC, trabalhos recentes, como o de Watson (2007), alertam quanto à dificuldade de incorporar a Teoria das Restrições à cultura das empresas.

No presente estudo, procurou-se demonstrar como essa teoria pode apoiar o processo de tomada de decisões em uma indústria de couros do interior de Santa Catarina, identificada, neste trabalho, como Indústria de Couros de SC, por questões de natureza gerencial. 
A empresa em análise possui várias décadas de experiência em seu ramo de atuação e caracteriza-se como um curtume de médio porte, de controle e administração familiar, produzindo e comercializando couros dos tipos wet blue, crust e acabado.

Com a realização de entrevista com o diretor dessa empresa de couros, foram identificadas situações de aplicação da Teoria das Restrições, demonstradas neste estudo por valores aproximados aos reais, a fim de preservar a essência das informações sobre preços praticados e mix de produtos.

Considerando as características peculiares a cada ramo de atividade industrial, foi levado em consideração o fator sazonalidade inerente às atividades da empresa analisada, no que se refere aos efeitos decorrentes da aplicação dos pressupostos da TOC nas situações objeto de demonstração.

A avaliação da aplicação da Teoria das Restrições nessa indústria foi desenvolvida pela investigação sobre o nível conhecimento da alta administração sobre o assunto, buscando identificar a existência de orientações formais, relacionadas à $T O C$, no processo de tomada de decisões dessa empresa. Posteriormente, utilizouse a demonstração de situações reais e a materialização de restrições relativas ao processo industrial de fabricação de couros.

A contribuição deste estudo empírico é revelar a utilização empresarial do modelo de raciocínio contido nesta teoria, o que permite aos pesquisadores verificar sua aplicação no contexto de uma realidade prática, não somente por modelos ou simulações de aplicação. Representa não só uma demonstração para a aplicação em indústrias semelhantes, mas também em outros ramos de atividade. Ao longo do estudo observa-se que mesmo uma aplicação informal dos seus pressupostos pode ser benéfica ao processo de gestão de uma empresa.

\section{Metodologia da Pesquisa}

A pesquisa caracteriza-se como exploratória, pois, conforme Gil (2002), esse modelo visa proporcionar maior familiaridade com um problema a fim de torná-lo mais explícito, ou construir hipóteses, e tem como objetivo o aprimoramento de idéias. Tende, ainda, a utilizar levantamento bibliográfico, entrevistas pessoais e a análise de exemplos. Esse é o delineamento deste estudo de caso, por se enquadrar nesse conceito.

No contexto das pesquisas exploratórias, Beuren (2006) comenta que estas contribuem para o esclarecimento de questões não abordadas de forma satisfatória anteriormente, permitindo o conhecimento do assunto com maior profundidade.

A base bibliográfica suportará a explicação quanto à Teoria das Restrições, bem como ao mundo dos curtumes. O estudo de caso aborda a aplicação prática, 
o uso da Teoria das Restrições na Indústria de Couros SC, efetuado com base em entrevista estruturada realizada com o diretor financeiro da companhia e dados contábeis por ele apresentados, permitindo a evidenciação empírica do uso dessa teoria e dos resultados dela decorrentes.

A entrevista estruturada baseia-se em um questionário uniformizado, com padrões de respostas pré-definidas, e pode ser feita pessoalmente ou por telefone, por exemplo. A entrevista reduz as interpretações erradas por parte do interrogador que as esclarece com o entrevistado (LAVILLE, 1999).

O instrumento de coleta de dados utilizado neste estudo foi um questionário aberto, uma vez que este atenderia adequadamente ao propósito dos pesquisadores em obter informações sobre aspectos importantes da empresa, tais como seu negócio, gerenciamento, nível de conhecimento e disseminação dos pressupostos da Teoria das Restrições, informações que poderiam não ser conhecidas caso fosse utilizado um questionário fechado, com respostas pré-estabelecidas, que não permitissem complementações.

A empresa estudada foi selecionada pela acessibilidade à alta administração e por representar um caso típico de aplicação da TOC. Gil (2002) explica que os critérios de seleção de casos variam segundo os objetivos da pesquisa, sendo identificadas três modalidades: estudo de caso intrínseco, instrumental e coletivo. O estudo de caso intrínseco é aquele em que o caso analisado constitui o próprio objeto da pesquisa, não havendo a preocupação com o desenvolvimento de alguma teoria. Esta representa a classificação em que se enquadra o presente estudo.

O referido autor comenta que se costuma utilizar um único caso quando o acesso a múltiplos casos é difícil, e o pesquisador tem a possibilidade de investigar um dos casos. Nessa situação, a pesquisa deveria ser reconhecida como exploratória. Essa característica se apresenta no presente trabalho.

As limitações da pesquisa são inerentes ao estudo de caso, em que generalizações dos resultados não são possíveis para a totalidade dos casos com características semelhantes. De acordo com Gil (2002), o estudo de caso não é adequado para efetuar mensurações a respeito do nível de relações entre variáveis, muito menos para verificação de relações de causalidade entre elas.

Cabe destacar, ainda, que não é proposta do estudo criar novas situações, complementar ou aprofundar o uso da Teoria das Restrições na empresa, mas entender sua utilização e analisar os efeitos da aplicação de seus pressupostos no processo de tomada de decisão dos gestores.

\section{Processo Industrial do Couro}

A indústria brasileira de couro é reconhecida com uma das mais avançadas do mundo, operando com mão-de-obra qualificada. Atualmente, sofre um processo 
de mudança de trajetória, deixando um pouco seu antigo foco em calçados, cuja fabricação utiliza hoje diversos materiais sintéticos e avançando para o mercado automotivo, moveleiro e de artefatos (PORTAL DO AGRONEGÓCIO, 2007).

A fabricação do couro inicia-se na atividade pecuária, seguida do abate dos animais, descarne nos abatedouros e aplicação de conservantes. A pele dos animais, nessa etapa, é tratada nos frigoríficos ou vendida aos curtumes, onde será submetida a outros processos industriais para a obtenção do couro (PEIXOTO et al., 2002).

Ainda segundo a mesma fonte, $60 \%$ das vendas se concentram neste segmento, especialmente em exportações para China, Itália e Estados Unidos.

Empresas que processam couro são denominadas curtumes e são caracterizadas conforme a etapa de processamento do couro:

- Curtume de Wet Blue - Primeiro processamento, após o abate, quando é despelado, são retiradas gordura e graxa, e o couro cru é banhado em cromo, deixando o produto com tom azulado e molhado.

- Curtume de Semi-Acabado - O couro Wet blue submetido a processamento industrial leve, que permita futuras aplicações de tintas, relevo e espessura. Possui valor agregado maior que o wet blue e é conhecido como couro crust (semi-acabado).

- Curtume de Acabamento - Transforma o couro crust em couro acabado. É remetido ao cliente como todas as características que constarão do produto final, por exemplo, o couro acabado para uma bolsa, saída do curtume com a cor e relevo final. Caberá à indústria de acessório o corte e a montagem do produto.

- Curtume Integrado - Realiza todas as etapas, do couro cru ao acabado (op. cit.).

\section{Mercado de artigos de couro}

Cada tipo de couro tem um mercado: couros semi-acabados e, especialmente, os acabados, são confeccionados conforme necessidades do comprador; o cru e o wet blue são comercializados como commodities (PEIXOTO et al., 2002).

O mercado de couro cru está diretamente relacionado ao de carne bovina, que depende do poder de compra, da demanda e do preço de carnes substitutas, além de ser influenciado pela demanda do mercado internacional e da capacidade de estocagem. Outros fatores de influência são os surtos de epidemias de doenças, inundações ou secas em áreas de criação, capazes de provocar redução da oferta e reflexos sobre o preço (BNDES, 2007).

No Brasil, percebe-se que o mercado de estofamentos automotivos e residenciais tem potencial para crescer. Todavia, trata-se de mercado muito rigoroso 
no quesito qualidade, porém disposto a remunerar, à altura, os fornecedores que atendem aos seus elevados critérios. Algumas empresas estão especializando suas atividades neste segmento. O mercado automotivo é considerado de alto valor agregado e bastante exigente. $\mathrm{O}$ couro como revestimento é considerado um status e aumenta o valor dos veículos. É muito utilizado em países desenvolvidos, tanto em bancos como em revestimentos, e aumentada a aplicação em países em desenvolvimento (PEIXOTO et al., 2002).

A relação com montadoras requer estreita ligação entre elas e os curtumes, incluindo acompanhamento dos pedidos e da qualidade exigida, bem como atendimento aos prazos estabelecidos. O couro vem sofrendo com a concorrência de materiais sintéticos no mercado de calçados, mas ainda é forte no nicho de artigos de luxo, tais como calçados de grife e acessórios (op. cit.).

A Europa é o continente com maior oferta de couro acabado, com destaque para Itália, Espanha e Portugal. A Itália constitui o parâmetro da indústria de couros em termos de acabamento e qualidade. A indústria europeia destaca-se pela fabricação de produtos diferenciados, com marcas fortes e reconhecida tecnologia de processo e organização da produção. Outro segmento em expansão, que utiliza muito o couro, é o de calçados de segurança que apresenta um melhor atendimento a várias exigências técnicas simultaneamente (PEIXOTO et al., 2002).

Apesar do crescimento do mercado de couros e do aumento da produção em nível mundial, existem restrições às importações e exportações decorrentes de motivos sanitários, ambientais e econômicos. Há expectativas de que as restrições de caráter ambiental tornem-se mais rigorosas com relação ao uso de práticas agressivas ao meio ambiente. A concorrência global, a qualidade do produto e a preservação do meio ambiente são alguns dos desafios que esse segmento de atuação enfrenta para desenvolver-se ainda mais (op. cit.).

\section{A indústria de couros no Brasil}

Segundo o Ministério do Desenvolvimento, Indústria e Comércio Exterior - MDIC (2008), o Brasil possui o maior rebanho comercial do mundo com um número superior a 198 milhões de cabeças de gado de corte. Existem na atualidade cerca de 800 empresas atuando na produção de couros e peles bovinas.

Ainda, de acordo com o MDIC (2008), estima-se que este setor empregue diretamente mais de 44.700 trabalhadores, com uma produção de quase 40 milhões de peles/ ano, ou seja, algo como 18\% da produção total mundial. O País é líder na tecnologia de manufatura (op. cit.).

A produção brasileira de couros concentra-se basicamente nas regiões Sul e Sudeste, as quais, juntas, respondem por cerca de $70 \%$ da produção total e registram o maior número de curtumes (BNDES Setorial, 2002). 
O Brasil é o terceiro colocado no ranking mundial de produção de couros, atrás apenas dos Estados Unidos e da União Europeia, e é um dos líderes mundiais na exportação desses produtos. Entretanto, atua com perfil de pouca agregação de valor na produção. Cerca de $80 \%$ do volume total é exportado em estágio primário de curtimento, e apenas $20 \%$ como produto inteiramente manufaturado (MDIC, 2008).

O mercado mundial produz aproximadamente 220 milhões de peles por ano. O Brasil exportou, em 2004, aproximadamente 26 milhões de peles nos diversos estágios da produção. As empresas de couros tendem a se localizar nas regiões com maior produção e abate bovino (MDIC, 2008).

No caso de transações comerciais envolvendo couro acabado, sua configuração vem modificando-se ao longo dos anos. De acordo com dados do BNDES (2007), na década de 1980, no Brasil, 70\% do couro era utilizado pela indústria de calçados, ficando os $30 \%$ restantes para artefatos, vestuário, estofamentos e outros produtos. Atualmente, a estimativa do Centro das Indústrias de Curtumes do Brasil (CICB) é de que $25 \%$ do couro sejam utilizados pelos calçadistas; $15 \%$, para artefatos, vestuário e outros produtos; e $60 \%$, pela indústria automobilística e moveleira.

\section{A Teoria das Restrições - TOC}

A Teoria das Restrições (Theory of Constraints - TOC) foi criada pelo físico israelense Eliyahu Goldratt. Após estudo envolvendo o planejamento industrial de uma empresa, que gerou o software OPT (Optimized Production Tecnhology), escreveu, com Jeff Cox, na década de 1980, o livro The Goal, que no Brasil ficou conhecido como A Meta.

O livro é um romance que mostra as dificuldades de um gerente de fábrica em administrá-la, o que poderia até desencadear seu fechamento pelos maus resultados até então apresentados. Ao descobrir os princípios da TOC, apresentados de forma sutil no texto, o gerente consegue recuperar a competitividade. Resolve problemas de logística e posteriormente elabora um novo método de administração da produção da fábrica.

É interessante observar que Goldratt e Cox (1990) começam a abordagem do problema da empresa em A Meta com o personagem-gerente tentando descobrir e identificando a meta, o objetivo: "a meta de uma organização de produção é ganhar dinheiro...".

Diversos conceitos e pressupostos norteiam a TOC e precisam ser compreendidos para o entendimento da lógica gerencial que Goldratt propõe, bem como o entendimento de sua aplicação nos casos apresentados no presente estudo. Os conceitos primários, oriundos do estudo citado, que culminou com o livro A Meta, 
vêm sendo estudados e revistos pela academia, em especial em artigos estrangeiros que apresentam a evolução desta teoria e possibilidades de sua aplicação apresentadas ao longo de tantos ano e estudos realizados (KIM, 2003; WATSON, 2007; MABIN, 2008).

Mabin (2003) destacou, em estudo analítico realizado sobre 80 casos de sucesso de aplicação da TOC evidenciadas em artigos internacionais, que muitas mudanças intangíveis foram apontadas, como: redução do caos e estresse; melhor funcionamento das equipes e mais envolvimento dos funcionários; mais flexibilidade e responsabilidade; mais satisfação de empregados e melhora na qualidade dos trabalhos executados por estes. Explica que não foram analisadas profundamente na pesquisa, mas que poderiam ser explicadas pelo foco da TOC no desempenho global da empresa.

O pressuposto inicial é aquele apresentado em A Meta de que a empresa não deve se afastar de seu objetivo de auferir lucro e, dessa forma, os custos fixos são deixados em segundo plano, devido à dificuldade para se efetuar rateios e, por essa teoria, são secundários para a precificação dos produtos, que seria feita pelo próprio mercado (COGAN, 2007).

Goldratt (2002) demonstra o conceito de produtividade como a realização do ato de aproximar uma empresa da sua meta. Corbett (2005) ressalta que, no contexto da Teoria das Restrições, algo é produtivo somente quando ajuda o sistema a caminhar em direção a sua meta. Dessa forma, um aumento de produtividade só existiria efetivamente quando aumenta a lucratividade da empresa.

Outro conceito primordial na teoria é o de gargalo. Os recursos existentes para a geração de resultados são subdivididos em categorias: gargalos, não gargalos e recurso com capacidade restrita. $O$ primeiro limita a produção do sistema. O não gargalo é o recurso com capacidade superior ao gargalo. $\mathrm{O}$ nível de utilização dos recursos não gargalo não é determinado pelo seu potencial, e sim por outras restrições do sistema. Por último, o recurso com capacidade restrita é aquele que poderá se tornar um gargalo no futuro, dependendo do gerenciamento (COGAN, 2007).

Essas restrições impedem a plena utilização dos diversos recursos utilizados após aquele com limitação. Uma matéria-prima com limitações no fornecimento em dado momento, torna o equipamento que a processa subutilizado. O gargalo é a matéria-prima e o equipamento é o recurso não-gargalo. A mesma matéria-prima pode ser apenas um recurso com capacidade restrita, caso ainda não esteja sendo demandado, mas no futuro pode se transformar em um gargalo.

A teoria pressupõe que existe sempre alguma restrição no produto, que limita as receitas de vendas desse produto. Pode ser limitação na produção, na logística, nos materiais, ou até mesmo na demanda por ele. Corbett (2005) cita outros fatores restritivos, tais como minutos disponíveis de um recurso, número 
de pessoas à disposição da empresa ou a presença de determinada habilidade, no caso de empresas prestadoras de serviços.

No caso das empresas fabris, Goldratt (2002) explica que se deve procurar balancear o fluxo de produto pela fábrica com a demanda do mercado, o que não significa necessariamente a exigência de aumento na capacidade. Isso significa a busca pela máxima utilização dos fatores envolvidos no processo de produção, entre eles matéria-prima, mão-de-obra e máquinas.

Identificar tais recursos dentro do sistema, reconhecer que existe uma dependência entre estes recursos na cadeia produtiva são outros pressupostos da TOC. Corbett (2005) explica que a meta de administrar o sistema se torna mais fácil quando se admite a existência de interdependências entre as diversas variáveis que o compõem. Quando se atinge essa percepção, verifica-se a possibilidade de administrar o sistema adequadamente, controlando as variáveis que ditam o desempenho do sistema, ou seja, suas restrições.

Guerreiro (1999) reforça essa idéia ao apontar que existem diversas categorias de restrições no ambiente industrial, entre eles o mercado, a capacidade, a logística, o gerenciamento e o comportamento, e tais gargalos limitam o processo de produção, devendo ser reconhecidos os relacionamentos entre um recurso gargalo e um não gargalo.

É importante observar que os gargalos não representam elementos necessariamente ruins ou bons em um dado sistema. Há a necessidade de saber utilizálos no adequado controle de fluxos do sistema até o mercado, de modo a atender à demanda existente e aumentar o ganho para a empresa. Os gargalos ditam a dimensão do inventário assim como os ganhos (GOLDRATT, 2002).

Cogan (2007) destaca que as medidas consideradas tradicionais não são práticas à aplicação nas operações diárias, mas que a Teoria das Restrições desenvolveu um conjunto diferente de medidas que se relacionam diretamente com aquelas: Ganho (G), Inventário (I) e Despesas Operacionais (DO). Para Corbett (2005), cada decisão a ser tomada pelos administradores deverá levar em consideração seu impacto nessas três medidas.

Ganho $(\mathrm{G})$ corresponde à taxa pela qual o sistema gera dinheiro por meio das vendas. Vendas e não produção, pois o que não foi vendido não gera caixa para a empresa. Assemelha-se à margem de contribuição contábil (receita de venda menos custo variável), porém considerando a mão-de-obra direta como despesa fixa (COGAN, 2007).

Ganho $=$ Venda - Material Direto

O dinheiro investido em qualquer compra de bens que se pode vender é o Inventário (I). Distingue-se do conceito contábil clássico, que englobaria apenas estoques, pois inclui qualquer bem, não somente estoques. Entretanto não considera qualquer acréscimo ao valor, tais como mão-de-obra ou despesas. Nem 
mesmo a depreciação é considerada (COGAN, 2007).

Despesas Operacionais (DO) representa o dinheiro gasto para transformar o inventário em ganho, como a depreciação do inventário que é convertida em despesa operacional. Corresponde a custos e despesas fixas mais mão-de-obra direta na Contabilidade tradicional (COGAN, 2007). Nessa linha de raciocínio, Ganho é o que entra no sistema, inventário é o dinheiro que está no sistema e despesa operacional é o dinheiro desembolsado para que se obtenha o ganho.

Como a prioridade da TOC é "maximizar o ganho, depois minimizar o inventário e as despesas operacionais, nesta ordem" (COGAN, 2007), porém observando as restrições existentes no sistema e avaliando ganhos, é imprescindível a focalização nestas três medidas por aqueles que desejam implementá-la no gerenciamento de negócios.

As medidas clássicas utilizadas para aferir com precisão o desempenho econômico das organizações produtivas, tais como giro dos estoques, despesas totais, vendas totais, cumprimento de programações e prazos de entrega, são consideradas deficientes pela TOC. Não significa que essas medidas não constituam elementos importantes na avaliação do desempenho da empresa; mas há outras medidas que demonstram ter caráter preponderante para a melhoria do desempenho e mesmo para a continuidade da organização. Entre elas, destacam-se as medidas centrais de avaliação: Fluxo de Caixa, Lucro Líquido e Retorno sobre o Investimento (RSI) (CORBETT, 2005).

Nessa linha, verifica-se que a medição do alcance dessa meta se dá pelo lucro líquido, acompanhado pelo retorno sobre o investimento, que mostra a relação entre lucro e o investimento realizado, e ainda o fluxo de caixa, uma vez que sem recursos financeiros disponíveis não há sobrevivência em qualquer empresa. Cabe à administração da empresa detectar a relação lógica das principais medidas com a meta da empresa de ganhar dinheiro e dessa forma garantir a sua continuidade.

De acordo com Corbett (2005), um dos pressupostos da TOC é a possibilidade de verificar o impacto das decisões da administração nas despesas da empresa, a partir de uma análise caso a caso. Esse pressuposto elimina a necessidade de se buscarem bases de alocação para aferir a variabilidade dos custos em relação aos produtos. Como citados anteriormente, os custos fixos não são o aspecto principal desta teoria, mas, por não serem rateados, podem ser avaliados de forma independente.

Por fim, a TOC supõe que no curto prazo a capacidade é limitada e os gargalos inevitáveis. Há uma estabilidade momentânea nas características da produção, a análise da situação seria num dado momento, isto é, no curto prazo.

Como resume Huefner (2008), a administração busca melhorar ao menos uma das medidas financeiras: aumentar ganho, reduzir despesas operacionais e 
reduzir estoques, sem deixar de lado as demais, isto é, aumentar receita, o Ganho, enquanto mantém os níveis de custos (Despesas Operacionais) e a base dos ativos (Inventário).

A TOC apresenta uma forma de raciocínio complementar à dita tradicional Contabilidade de Custos, em que o ganho unitário seria a principal observação a fazer, calculada como preço de venda menos custos de matéria-prima e seriam analisados individualmente. No entanto, podem e devem ser analisados em conjunto, visto que a teoria preconiza a exploração da restrição para que se alcance a meta da empresa, que é ganhar dinheiro e, para tal se quer "extrair o máximo de dinheiro daquelas que coisas que nos limitam, a restrição" (GOLDRATT, 1991, p.69).

Uma lógica derivada da $T O C$, para a redução dos gargalos, é a chamada tambor-pulmão-corda, também descrita em A Meta. Cogan (2007) explica que o tambor seria o recurso com maior restrição de capacidade, que ditaria o ritmo dos demais. O "pulmão de tempo" serviria para manter o recurso gargalo ocupado durante todo o tempo pré-determinado, protegendo o ganho da empresa. A corda completa o raciocínio, pois assegura que o inventário não cresça além do nível determinado pelo pulmão.

Em uma analogia, numa tropa com diversos soldados, o mais lento é colocado no meio da fila, com um tambor, ditando as passadas dos demais. $\mathrm{Na}$ produção, o tambor seria a regra de quando e quais produtos seriam processados. O pulmão seriam os materiais disponibilizados antes do gargalo, para mantê-lo sempre operante, como um estoque regulador. A corda seria a limitação de material liberado pela fábrica (COGAN, 2007).

É possível observar que uma das principais características da TOC é o seu processo de otimização contínua, em que há uma focalização nas cinco etapas a seguir, conforme resumido por Goldratt (1990):

1. Identificar a(s) restrição/ões do sistema, isto é, verificar quais elementos afetam de forma restritiva a melhoria no desempenho do sistema. Por exemplo, nos casos em que a demanda do mercado for superior à capacidade da empresa, verifica-se a existência de recursos com restrição de capacidade (RRC), que precisam ser identificados. Quando, ao contrário, a demanda do mercado for inferior à capacidade, a restrição será o próprio mercado.

2. Decidir como explorar a(s) restrição/ões do sistema, uma vez que a restrição presente no sistema já é conhecida, é necessário providenciar para que não faltem recursos para atender os RRCs, ou seja, os itens não gargalo devem existir em quantidade suficiente para suprir os gargalos.

3. Subordinar tudo à decisão anterior.

4. Elevar a(s) restrição/ões do sistema, o que significa considerar várias 
alternativas para investir na restrição, ampliando sua capacidade, seja pela aplicação de mais recursos, na forma de tempo ou investimentos em recursos adicionais idênticos. Provavelmente, isso ocasionará o aparecimento de outra restrição em uma outra localidade do sistema.

5. Se num passo anterior uma restrição for quebrada, volte ao passo $1 \mathrm{sem}$ deixar que a inércia cause uma restrição no sistema; isto implica a necessidade de se reavaliar regularmente as decisões tomadas nas etapas anteriores, pois as restrições mudarão de posição no sistema, exigindo constante acompanhamento do desempenho do sistema.

Dessa forma, a idéia é sempre calcular o ganho por unidade restrita, o que leva à otimização desses recursos, representada pelo ganho dividido pelo consumo da unidade restrita. Esse cálculo permite o uso máximo do recurso gargalo, subsidiando uma decisão sobre que bem produzir com o recurso restrito, para que seja plenamente utilizado. É importante lembrar que a reavaliação contínua se faz necessária, evitar a inércia, pois segundo Goldratt (1991, p. 90), “o que se deve fazer é reexaminar qual produto contribui mais, através da restrição”, o que pode mudar completamente o cenário anterior, pelas simples divisão de unidades monetárias de ganhos pela unidade de recurso restrito.

\section{Ganho por Unidade Restrita $=$ Ganho Unitário / Unidade Restrita}

A TOC é um sistema multifacetado que tem sido desenvolvido para auxiliar pessoas e empresas a pensar sobre seus problemas, desenvolver soluções avançadas e implementá-las com sucesso (MABIN, 2003). Tal conceito demonstra a característica da teoria de despertar uma reflexão constante que visa à redução dos problemas inerentes ao contexto empresarial, cujos recursos não são ilimitados e nem os cenários são imutáveis.

Segundo Watson (2007), os fundamentos da TOC recebem críticas que atrapalham sua disseminação e seriam desafios futuros: na visão acadêmica, a teoria produz resultados possíveis, mas não viáveis; carência de um meio de determinação do custo do produto e estabelecimento de preços; e visão de curto prazo. O mesmo estudo aponta um problema em relação aos estudiosos e disseminadores da teoria, referente à dificuldade de obtenção do suporte gerencial em nível alto, que delegariam a implementação a níveis gerenciais médios, mesmo que a $T O C$ requeira uma mudança organizacional, filosófica, prática e de medição de desempenho.

Nessa consideração de Watson (2007), é observada a necessidade de conhecimento pelo tomador de decisão para que os fundamentos aplicados alcancem os objetivos preconizados na Teoria das Restrições: soluções que levam a empresa à meta, ao lucro. 


\section{A Teoria das Restrições no Processo Industrial de Couros da Indústria de Couros de Santa Catarina}

\subsection{Contexto}

A avaliação da aplicação da Teoria das Restrições em uma indústria de couros, desenvolvida neste estudo de caso, foi divida em três etapas:

1. a etapa: investigar o nível de conhecimento que a alta administração possuía sobre a TOC e identificar a existência de orientações formais, relacionadas à $T O C$, no processo de tomada de decisões da empresa.

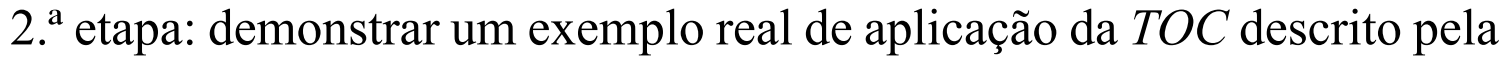
empresa, através da utilização de dados adaptados, mas compatíveis aos reais.

3. ${ }^{\text {a }}$ etapa: testar a aplicação da TOC diante da possibilidade de materialização de uma restrição inerente ao processo industrial de couros.

As informações obtidas para realização deste estudo de caso foram obtidas por entrevista ao Diretor Industrial da Indústria de Couros de SC.

A empresa é um curtume de médio porte, de controle e administração familiar, com várias décadas de experiência e sucesso na industrialização e comercialização de couro wet blue, crust e acabado.

No segmento couro acabado há uma série de produtos que podem ser desenvolvidos, de acordo com o processo industrial a que foi submetido, resultando em produtos com diferentes valores agregados.

\subsection{Primeira Etapa: O nível de Conhecimento da Administração sobre a Teoria das Restrições}

Nesta etapa, foi realizada entrevista, no início de 2008, para levantamento sobre o conhecimento do diretor financeiro da empresa sobre a Teoria das Restrições e detalhamento das situações em que esta é ou já foi aplicada em sua gestão. A entrevista com a alta administração é compatível com a visão de Watson (2007), relacionada à necessidade de implementação da teoria nesse nível, que então ampliaria sua aplicação aos demais níveis da empresa.

O questionário aberto, constante no Quadro 1, foi complementado por perguntas e confirmações do entendimento dos pesquisadores quanto às respostas, durante a entrevista.

O diretor industrial entrevistado é sócio da empresa, graduado em Engenharia Civil e pós-graduado, no exterior, em Planejamento Estratégico. Conheceu 
a Teoria das Restrições há cinco anos por meio da publicação A Meta, de Goldratt e Cox, e considera a TOC útil para o processo de formulação de estratégias e tomada de decisões.

\section{Quadro 1: Questionário}

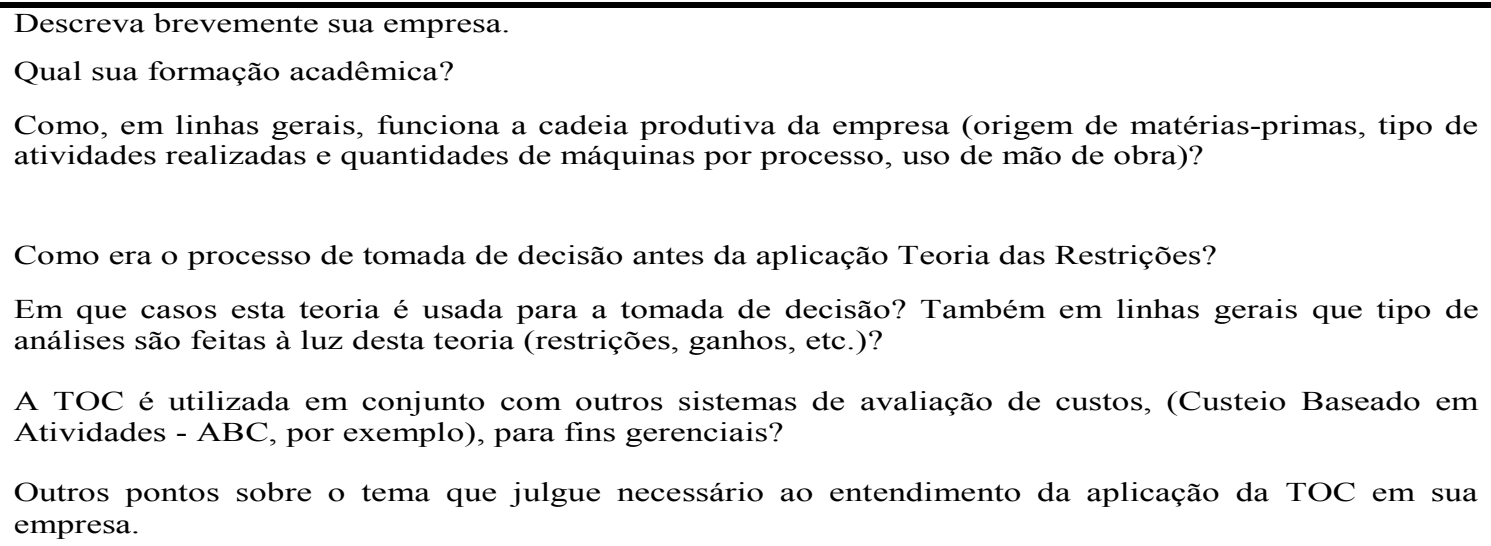

Fonte: Elaborada pelos autores.

O referencial teórico apresentado se atém aos fundamentos centrais da teoria, seu núcleo original, sem considerar sua evolução ao longo dos anos descrita por Watson (2007), visto que a aplicação prática do gestor no curtume encontrase atualmente nesse patamar. Não há avaliação de custos utilizando a TOC e o Activity-Based Costing ( $A B C)$, por exemplo.

Nesta etapa do estudo, o principal objetivo é destacar como a escolha de um modelo de análise pode influenciar a geração de informações para a tomada de decisões, e, porventura, incorrer o risco de alcançar resultados inferiores aos que poderiam ser atingidos se a construção da análise fosse diferente. Esse conceito foi incitado em Caplan (2005), onde um exemplo fictício ilustra como a interdependência entre produtos no processo de produção e seus custos associados desafiam a capacidade dos sistemas contábeis e de custeio nos moldes atuais de fornecer a melhor informação para tomada de decisões.

O conhecimento sobre a TOC não está difundido nos demais níveis hierárquicos da empresa e nem é utilizada como uma ferramenta formal de trabalho. Mas seus fundamentos estão sendo utilizados para aprimorar a metodologia de gestão da empresa, por enquanto, por intervenções do diretor industrial, que possui familiaridade com a teoria. Suas respostas, às questões apresentadas no Quadro 1, subsidiaram a elaboração das próximas etapas.

\subsection{Segunda Etapa: Aplicação da Teoria das Restrições com restrição na ca- pacidade de produção}

A TOC foi aplicada nas atividades da Indústria de Couros de SC para 
definição da melhor estratégia de negócio diante de um pedido de um cliente. $\mathrm{O}$ cliente contatou o setor de vendas do curtume e solicitou orçamento de um grande pedido do produto da Classe $\mathrm{C}$, economicamente interessante, mas com um obstáculo: na situação atual, não poderia ser atendido.

A seguir, encontra-se a Tabela 1 com a relação de produtos manufaturados e seus respectivos preços unitários, ganhos unitários em percentuais e em reais, proporção das vendas de cada produto em relação ao faturamento mensal e a quantidade de horas necessárias em um tipo de equipamento essencial ao processo produtivo. Para resguardar os dados estratégicos da empresa, cálculos ilustrativos foram elaborados com números aproximados, mas que preservam a lógica da situação real.

Tabela 1: Produtos e Margens de Ganho por Metro Quadrado (m2)

\begin{tabular}{|c|c|c|c|c|}
\hline Classe & $\begin{array}{c}\text { Preço } \\
\text { Unitário }\end{array}$ & $\begin{array}{c}\text { Ganno } \\
\text { Unitário } \\
\text { Percentual }\end{array}$ & $\begin{array}{c}\text { Ganno } \\
\text { Unitário em } \\
\text { Reais }\end{array}$ & $\begin{array}{l}\text { Uso de Minutos de } \\
\text { Máquinas Modelo X }\end{array}$ \\
\hline $\mathrm{A}$ & $\mathrm{R} \$ 109,00$ & $35 \%$ & $\mathrm{R} \$ 38,15$ & 18 \\
\hline B & $\mathrm{R} \$ \quad 95,00$ & $30 \%$ & $\mathrm{R} \$ 28,50$ & 15 \\
\hline $\mathrm{C}$ & 81,00 & $32 \%$ & $\mathrm{R} \$ 25,92$ & 12 \\
\hline $\mathrm{D}$ & 67,00 & $28 \%$ & $\mathrm{R} \$ 18,76$ & 9 \\
\hline $\mathrm{E}$ & 54,00 & $25 \%$ & $\mathrm{R} \$ 13,50$ & 6 \\
\hline F & 50,00 & $20 \%$ & $\mathrm{R} \$ 10,00$ & 0 \\
\hline
\end{tabular}

Fonte: Elaborada pelos autores.

O ganho unitário é entendido como o resultado da subtração dos custos diretos do preço de venda (os materiais-diretos são os únicos custos considerados variáveis):

\section{Ganho Unitário $=$ Preço de Venda - Custos Diretos}

O gestor tem um novo cenário possível, que o leva a considerar algumas proposições: a empresa pode atender a este pedido? Está configurada a existência de algum gargalo neste processo?

Diante do significativo pedido do cliente de $39.000 \mathrm{~m}^{2}$ de couro Classe C, para ser entregue em seis lotes iguais nos próximos 6 meses $\left(6.500 \mathrm{~m}^{2}\right.$ por mês $)$ , foi identificada uma restrição à capacidade produtiva do parque industrial de máquinas Modelo X, necessária à confecção das peças solicitadas.

Aceitar o pedido com essa restrição afetaria seu mix de produtos e geraria impacto negativo na empresa, visto que esta trabalha sob encomendas que são realizadas com certa antecedência. Deixar de produzi-las, seria inviável. Recusar o pedido, poderia prejudicar o relacionamento com o cliente, além de ceder mercado para um concorrente.

Nesse cenário, o conhecimento da TOC auxiliou a administração na identificação de um recurso restrito e subsidiou a avaliação quanto à expansão 
de seu parque industrial, ou seja, a TOC ofereceu uma nova visão: ampliação da capacidade produtiva mediante aquisição de outro equipamento similar ao equipamento com restrição, desde que o cliente aceitasse assinar um contrato de longo prazo, que garantiria uma produção capaz de gerar retorno ao investimento que seria realizado.

Conforme a Tabela 1, para produzir $6.500 \mathrm{~m}^{2}$ ao mês de couro classe $\mathrm{C}$, para atender ao novo pedido, seriam necessários 78.000 minutos (1.300 horas) por mês de máquinas Modelo $\mathrm{X}$, considerando que o preparo da matéria-prima demora alguns dias antes desta etapa.

Tabela 2: Capacidade Mensal de Utilização das Máquinas Modelo X para Produtos C

\begin{tabular}{crr}
\hline Utilização & Minutos & \multicolumn{1}{c}{ Horas } \\
\hline Capacidade Total de 12 máquinas & 480.000 & 8.000 \\
$(-)$ Utilização Atual & 462.000 & 7.700 \\
$(=)$ Horas Disponíveis & 18.000 & 300 \\
$(-)$ Necessidade para atendimento ao pedido & 78.000 & 1.300 \\
$(=)$ Falta de Capacidade do Parque & 60.000 & 1.000 \\
\hline
\end{tabular}

Fonte: Elaborada pelos autores.

Com os cálculos apresentados na Tabela 2, baseados em dados apresentados na Tabela 1, conclui-se que o parque de máquinas Modelo X representa um gargalo, pois está com sua utilização a 96,3\%. Como citado anteriormente, a busca por um melhor mix de produtos não seria aplicável, por existirem pedidos contratados que não podem ser descartados. Foram identificadas como recurso com restrição de capacidade (RRC) máquinas Modelo X, que devem receber tratamento para a solução.

É necessário responder ao cliente se a companhia de couros aceitará o pedido. Existe a opção de investir em dois novos equipamentos ao custo de $\mathrm{R} \$$ 750.000,00 cada, com capacidade de uso individual de 40.000 minutos por mês, para que seja alcançada a produtividade de mais 1.000 horas ao mês. Essa nova aquisição aumentará o custo fixo para a empresa, que se tornaria um aumento das Despesas Operacionais, via depreciação. Para simplificação, considerou-se desnecessária qualquer manutenção no primeiro ano de uso.

O ganho por minuto da máquina, apurado com dados da Tabela 1, representa o valor de venda vezes a margem, considerando a quantidade de horas usadas da máquina:

$(\mathrm{R} \$ 81,00 \times 32 \%) / 12$ minutos $=\mathrm{R} \$ 2,16$ por minuto

A Tabela 3 demonstrou que o investimento de $\mathrm{R} \$ 1.500 .000,00$ requer 694.444 de produção do produto Classe C para ser totalmente absorvido. Uma vez que o pedido é de $39.000 \mathrm{~m}^{2}$ ou $6.500 \mathrm{~m}^{2}$ durante seis meses consecutivos, e 
não há outra demanda concreta para o uso da máquina Modelo X, a alta administração da Indústria de Couros de SC decidiu negociar com o cliente um contrato de fornecimento de $6.500 \mathrm{~m}^{2}$ durante 9 meses (694.444 / 78.000).

Tabela 3: Análise de Proposta ao Cliente

\begin{tabular}{cc}
\hline Custo das novas máquinas $(\mathrm{a})$ & $\mathrm{R} \$ 1.500 .000,00$ \\
Ganho por minuto da máquina (b) & $\mathrm{R} \$ 2,16 /$ minuto \\
Custo / Ganho por minuto $(\mathrm{a} / \mathrm{b})$ & 694.444 minutos \\
Pedido mensal original & $6.500 \mathrm{~m}^{2}=78.000$ minutos por mês \\
Meses mínimos para o contrato & 9 meses \\
\hline
\end{tabular}

Fonte: Elaborada pelos autores.

Como um exemplo teórico dado por Guerreiro (2006), observando os princípios contidos na $T O C$ e sendo a restrição a hora-máquina, explorar a restrição significa buscar o maior ganho em dinheiro por hora-máquina. Exatamente este raciocínio é aplicado na indústria estudada.

Embora a aquisição de novas máquinas elimine a restrição relativa a horas por máquina, esse cálculo se faz importante como uma forma de análise do pedido específico do cliente, que solicitou um contrato de seis meses, cujo ganho viabilizaria apenas parte do valor da compra.

O cálculo subsidiou uma contraproposta: um contrato mínimo de 9 meses, que custearia a compra de novas máquinas e permitiria a ampliação do parque industrial. Esta ampliação é de interesse da empresa, pois seu volume de vendas está em crescimento, conforme informado na entrevista, e cria uma fidelidade do cliente por mais tempo.

Destaca-se que apurar o pedido mínimo em função da máquina se fez importante no curto prazo, visto que não havia intenção de realizar investimentos nesse período ou aumentar despesas operacionais.

O pedido do cliente não foi simplesmente recusado, e este cliente conseguiu ter um retorno breve quanto à possibilidade de atendimento à sua necessidade devido à agilidade nos cálculos. Houve a busca de maximização de ganhos, como preconiza a $T O C$, pois o novo volume de produção, com respectiva venda do produto $\mathrm{C}$, produzirá ganho incremental, sem redução dos resultados anteriores a esta operação.

A $T O C$ demonstra que há aumento de produtividade quando se chega mais próximo da meta: que, no caso, é auferir cada vez mais lucros e crescer ainda mais no mercado. Isso ocorrerá com a aceitação da proposta pelo cliente, pois haverá expansão de atividade já avaliada como lucrativa, bem como a conquista de uma parceria de longo prazo com um grande cliente. O gestor conseguiu, ainda, impedir o aumento de suas despesas operacionais, como preconiza a $T O C$, pois optou por 
custear a nova aquisição de equipamentos com um contrato de prazo maior.

Outro ponto de destaque em relação a essa solução é a possibilidade de aumento da produção, devido à sobra de horas disponíveis, que possibilitarão a busca por novos clientes. A decisão pela compra de novas máquinas, observado o quinto passo, leva a um novo gargalo, o mercado consumidor, que precisará ser explorado para maximização dos ganhos da companhia - o que representará um desafio e não um problema para a empresa, que está em pleno processo de crescimento, conforme entrevista.

Quando perguntado sobre como tomaria a decisão antes do seu conhecimento da $T O C$, o entrevistado respondeu que precisaria do auxílio de diversos funcionários com visões diferentes, o que demandaria mais tempo, tornando a decisão mais lenta.

Para a melhor aplicação da TOC é importante levantar rapidamente as possíveis restrições à aceitação de um pedido de produção, pois essas informações são primordiais para a formulação de uma decisão baseada nessa teoria.

Cabe salientar que a solução é momentânea, capaz de solucionar o problema no curto prazo, e que novos gargalos podem surgir, especialmente, em uma empresa como a estudada, que está em processo de expansão de atividades. Como descrevem os cinco passos, a busca deve ser por uma otimização contínua.

\subsection{Terceira Etapa: Aplicação da Teoria das Restrições com restrição na matéria-prima}

A Indústria de Couros de SC opera com seis diferentes classificações de couros em sua linha de produção. Essas classificações relacionam-se tanto à qualidade do material e quanto ao seu rendimento na linha de produção. Dessa forma, resultam em produtos finais com preços e finalidades diferentes.

Apesar de o abate bovino ocorrer durante todo o ano, há maior frequência no verão e redução no inverno devido ao período de engorda dos animais. Diante disso, os curtumes programam seu estoque de maneira que possam garantir sua produção da forma mais regular possível e ao melhor custo.

Embora haja a sazonalidade, o diretor esclareceu que não há um aumento grande de estoques de couro para esse período. A opção é realizar tal aumento em volumes pequenos e priorizar a captação de pedidos que permitam maior aproveitamento da matéria-prima. Entende-se aqui aproveitamento como o uso do couro para a fabricação de metragem de produto acabado e, sendo assim, o produto que tem $60 \%$ de aproveitamento indica que de cada metro de matéria-prima são obtidos apenas 0,60 centímetros de produto acabado, com $40 \%$ de perda.

Quando o recurso restrito é a principal matéria-prima, torna-se prioritário identificar sua melhor forma de alocação. Consequentemente, o mix padrão de 
produtos pode ser afetado. Nesse cenário, o curtume busca atender prioritariamente aos pedidos que tenham os maiores ganhos por unidade de recurso restrito, dentro do possível.

Tabela 4: Produtos e Margens de Ganho

\begin{tabular}{|c|c|c|c|c|c|c|}
\hline Classe & $\begin{array}{c}\text { Ganho } \\
\text { Unitário } \\
\text { em Reais }\end{array}$ & $\begin{array}{c}\text { Ganho } \\
\text { Unitário } \\
\text { Percentual }\end{array}$ & $\begin{array}{c}\text { Percentual } \\
\text { de } \\
\text { Aproveita- } \\
\text { mento } \\
\end{array}$ & $\begin{array}{c}\text { Metros de } \\
\text { Couro por } \\
\text { Unidade } \\
\text { Pronta } \\
\end{array}$ & $\begin{array}{c}\text { Ganho por } \\
\text { Unidade de } \\
\text { Recurso } \\
\text { Restrito }\left(\mathbf{m}^{2}\right) \\
\end{array}$ & $\begin{array}{c}\text { Preferência } \\
\text { na } \\
\text { Produção e } \\
\text { Venda } \\
\end{array}$ \\
\hline A & $\mathrm{R} \$ 38,15$ & $35 \%$ & $60 \%$ & 1,67 & $\mathrm{R} \$ 22,89$ & $2^{\mathrm{a}}$ \\
\hline B & $\mathrm{R} \$ 28,50$ & $30 \%$ & $70 \%$ & 1,43 & R\$ 19,95 & $3^{\circ}$ \\
\hline $\mathbf{C}$ & R\$ 25,92 & $32 \%$ & $90 \%$ & $\mathbf{1 , 1 1}$ & R\$ 23,33 & $\mathbf{1}^{\mathbf{o}}$ \\
\hline $\mathrm{D}$ & $\mathrm{R} \$ 18,76$ & $28 \%$ & $97 \%$ & 1,05 & $\mathrm{R} \$ 17,82$ & $4^{\circ}$ \\
\hline $\mathrm{E}$ & $\mathrm{R} \$ 13,50$ & $25 \%$ & $98 \%$ & 1,02 & $\mathrm{R} \$ 13,23$ & $5^{\circ}$ \\
\hline $\mathrm{F}$ & $\mathrm{R} \$ 10,00$ & $20 \%$ & $100 \%$ & 1,00 & $\mathrm{R} \$ 10,00$ & $6^{\circ}$ \\
\hline
\end{tabular}

Fonte: Elaborada pelos autores.

O foco, nessa situação apontada pela empresa, é também oriundo do conhecimento sobre a TOC: maximizar ganhos e minimizar inventário.

Considerando os dados apresentados na Tabela 4, apesar de o produto classe A apresentar o maior ganho unitário em reais e ser priorizado quando há abundância de matéria-prima, durante o inverno torna-se relevante avaliar também o seu percentual de aproveitamento.

A classe de produtos A gera ganho unitário de $\mathrm{R} \$ 38,15$, mas seu percentual de aproveitamento é de $60 \%(1,67)$. Essa combinação corresponde a ganho por unidade de recurso restrito de $\mathrm{R} \$ 22,89$, resultado entre a divisão do ganho unitário pelo fator de recurso restrito (couro). Sendo assim, no inverno (quando o abate bovino é menor), a classe de produtos $\mathrm{C}$, cujo ganho é de $\mathrm{R} \$ 25,92$ e o aproveitamento do couro é $90 \%(1,11)$, deve ser priorizada, pois resulta em ganho por unidade de recurso restrito de $\mathrm{R} \$ 23,23$ e maximiza o uso desse insumo durante esse período do ano e, portanto, o ganho do curtume.

A prioridade apontada depende da demanda pelos produtos elencados como de melhor aproveitamento, o que representa uma restrição de mercado, que é tratada por meio da negociação especial com os clientes nesse período de menor quantidade de couro cru.

O gestor da empresa entende que essas duas situações não esgotam as limitações, visto que, como preconiza a TOC, é necessário constante monitoramento de fatores internos e externos que interferem na cadeia produtiva, pois podem vir a se tornar uma nova restrição.

\section{Considerações Finais}


O presente estudo ratificou a afirmação citada por Cogan (2007, p. 44), de que a Teoria das Restrições pode sofrer críticas por conter enfoques abordados nos livros de custos há muito tempo, mas se trata de uma "técnica/teoria/fisolosofia que, para muitos especialistas (entre os quais Kaplan e Cooper), é o melhor modelo de tomada de decisão de mix de produtos de curto prazo". Revelou que o conhecimento da Teoria das Restrições (TOC) permite ao gestor tomar decisões mais ágeis e alinhadas com suas metas.

Permite observar que em empresas que produzem sob encomendas, modificar o mix de produtos não é uma decisão fácil, porém a utilização da TOC facilita a estruturação de análises lógicas na busca das restrições que porventura existam e atrapalhem os objetivos de maximizar os ganhos, como apresentado por Huefner (2008).

Adicionalmente, é necessário considerar as características peculiares ao ramo de negócio em que a organização atua. Na empresa em estudo, há o fator sazonalidade a ser considerado no que se refere à oferta de matérias-primas necessárias ao processo produtivo, que representa um recurso de capacidade restrita que poderá se tornar um problema em função do gerenciamento (COGAN, 2007).

$\mathrm{O}$ estudo demonstrou ainda que, mesmo não existindo uma aplicação metódica ou formal da TOC na empresa analisada, o conhecimento do administrador sobre a teoria básica pôde auxiliá-lo em suas atividades gerenciais, acelerando o processo de tomada de decisões.

Cabe ressaltar que, na companhia estudada, a aplicação dos fundamentos da TOC com resultados satisfatórios foi possível devido ao conhecimento dos seus princípios por parte do gestor de alto escalão, além da experiência adquirida à frente desse tipo de empreendimento, situação diferente da apontada por Watson (2007), a respeito de estudos sem apoio nesse nível. Sem essa premissa do conhecimento da alta administração, a utilização única e exclusiva dos fundamentos da $T O C$, sem que fosse efetuada uma análise coerente do cenário apresentado, poderia levar a decisões equivocadas.

As duas situações apresentadas comprovam que cálculos baseados na TOC podem demandar pouco tempo e auxiliam na observação mais clara da situação, ou seja, o uso da TOC pode ser um diferencial para a empresa que a aplica, visto que uma decisão sem uma análise dos fatores envolvidos pode representar a perda de um negócio. Demora na decisão, por desconhecimento ou por desatenção com gargalos, pode impedir a entrega de pedidos no prazo e acarretar problemas no relacionamento com clientes.

A primeira situação apresentada referente ao grande pedido de um cliente despertou no gestor a busca por um possível gargalo. A máquina foi identificada como um recurso gargalo por limitar a produção do sistema. Mesmo com maior quantidade de couro, não poderia atender ao pedido na situação atual no curto 
prazo.

Identificado o gargalo, o diretor buscou uma solução para essa restrição com base no ganho a ser auferido com as novas horas-máquina oriundas de equipamentos novos, conforme conceito da TOC. A solução foi a compra de outras máquinas condicionada a um contrato maior, visto que não havia objetivo de curto prazo de aquisição com recursos próprios.

O conceito de ganho por unidade de recurso restrito é aplicado na ocasião de falta ou redução no fornecimento de couro, em que foi apurado o melhor mix de vendas em função da maximização do uso do recurso restrito, o couro, apurado pela relação entre ganho unitário e respectivo uso por tipo de produto. Isso permitiu apurar as classes de couro que levam à maximização do ganho do curtume e devem ser priorizadas.

A avaliação por gargalos se aplica aos casos de análise da aceitação de novos pedidos, investimentos na fabricação de novas linhas de produtos, supressão de linhas de produtos com resultados deficitários, além da priorização de determinado produto componente de um mix em relação aos demais itens.

A TOC preconiza a reavaliação constante da presença e mudanças de localização de restrições no sistema (GOLDRATT, 1990), considerando o desempenho da empresa no curto prazo. Na empresa objeto da pesquisa, em que se considera a possibilidade de expansão de seu parque industrial, essa necessidade torna-se premente de forma a possibilitar o crescimento da companhia de modo sustentável.

Tal evidenciação empírica contribui para a prática na área de gestão de empresas. Alguns estudos desenvolvem a Teoria das Restrições sob a forma de simulação sobre sua aplicação, entretanto observar sua utilização no mundo real permite uma compreensão maior de sua finalidade, bem como abre perspectivas de estudos complementares em outros ramos de atividade, visto que a academia e as empresas podem interagir possibilitando o aprofundamento do conhecimento e experiência entre ambos.

Não foram apresentados pela empresa casos de restrições múltiplas, que demandariam esforços mais complexos para a solução, como o modelo de programação linear, todavia o caso atende às expectativas de demonstrar a aplicação prática dos conceitos, independente da complexidade de seus negócios.

Como sugestão de pesquisas futuras, propõe-se a utilização da TOC em outras atividades industriais e em empresas que produzam por escala, pois seria possível analisar o uso da teoria em relação a mudanças na ordem de processamento da produção para otimização dos processos de esTOCagem de produtos acabados, inexistente no presente estudo. Outra sugestão seria um estudo de caso onde houvesse a integração da TOC ao método de custeio ABC (Activity-Based Costing), conforme apresentado na literatura sobre o tema. 


\section{Referências}

BEUREN, Ilse Maria (Org.). Como elaborar trabalhos monográficos em contabilidade: teoria e prática. 3. ed. São Paulo: Atlas, 2006.

BNDES - Banco Nacional de Desenvolvimento Econômico e Social. Informe Setorial: A Indústria de Curtumes no Brasil, out./2007. Disponível em: http:// www.bndes.gov.br. Acesso em: 24/02/2008.

CAPLAN, D.; MELUMAD, N. D.; ZIV, A. Activity-Based Costing and Cost Interdependencies among Products: The Denim Finishing Company. Issues in Accounting Education. Vol. 20, No. 1. February, 2005. p. 51.62.

CASTRO, G. S.; RODRIGUES R.; AMARAL M.; COGAN, Samuel. Os princípios da Teoria das Restrições aplicados à geração de energia termelétrica. In: $8^{\circ}$ Congresso USP de Contabilidade e Controladoria, 2008, São Paulo. $8^{\circ}$ Congresso USP de Contabilidade e Controladoria. São Paulo: USP, 2008.

COGAN, Samuel. Contabilidade Gerencial: uma abordagem da Teoria das Restrições. São Paulo: Saraiva, 2007.

CORBETT, Thomas. Bússola Financeira: O processo decisório da Teoria das Restrições. São Paulo: Nobel, 2005.

EMBARQUES de Couro devem ultrapassar US\$ 2 bi em 2007. Disponível em: http://www.portaldoagronegocio.com.br. Acesso em: 08/01/2008.

GIL, Antônio Carlos. Como elaborar projetos de pesquisa. 4. ed. São Paulo: Atlas, 2002.

GOLDRATT, Eliyahu M. What is this thing called theory of constraints and how should it be implemented? Great Barrington: North River, 1990.

A síndrome do palheiro: garimpando informação num oceano de dados. São Paulo, C. Fullmann, 1991.

GOLDRATT, Eliyahu e COX, Jeff. A Meta. 4. ed. rev. São Paulo: Claudiney Fullmann, 1990.

Paulo, 2002.

. A Meta: Um processo de melhoria contínua. 2. ed. Ed. Nobel: São

GUERREIRO, Reinaldo. A meta da empresa: seu alcance sem mistérios. São 
Paulo: Atlas, 1999.

. Gestão do lucro. São Paulo: Atlas, 2006.

HUEFNER, Ronald J.; LARGAY III, James A. The role of accounting information in revenue management. Business Horizons, n. 51, p. 245-255, 2008.

KIM, Seonmin; MABIN, Victoria Jane; DAVIES, John. The theory of constrains thinking process: retrospect and prospect. International Journal of Operations \& Production Management, n. 28, p. 155-184, 2008.

LAVILLE Christian; DIONEE, Jeaon. A Contrução do Saber - Manual de metodologia da pesquisa em ciências. Editora. Porto Alegre: Atlas/UFMG, 1999

MABIN, Victoria J. e BALDERSTONE, Steven, J. The performance of the Theory of Constraints methodology: Analysis and discussion of successful TOC aplication. International Journal of Operations \& Production Management, n. 23, p. 568-595, 2003.

MARTINS, Fábio Augusto. O Processo de Raciocínio da Teoria das Restrições na Indústria Moveleira de Pequeno Porte: Um Estudo de Caso. Dissertação apresentada ao Programa de Pós-Graduação em Engenharia de Produção da Universidade Federal de Santa Catarina como requisito parcial para a obtenção do grau de Mestre em Engenharia de Produção. Orientador: Prof. Antonio Cezar Bornia, Dr. Florianópolis, 2002.

MINISTÉRIO DO DESENVOLVIMENTO, INDÚSTRIA E COMÉRCIO. Cadeias Produtivas: Couro, Calçados e Artefatos. Disponível em: http://www. mdic.gov.br. Acesso em: 24/02/2008.

MINISTÉRIO DO DESENVOLVIMENTO, INDÚSTRIA E COMÉRCIO. Fórum de Competitividade da Cadeia Produtiva de Couro, Calçados e Artefatos. Brasília, DF, 2005. Disponível em: http://www.mdic.gov.br. Acesso em: 24/02/2008.

PEIXOTO, Gabriel B.T. et al. BNDES Setorial. Panorama do Setor de Couro no Brasil. Rio de Janeiro, n.16, p.57-84, set 2002. Disponível em: http://www. bndes.gov.br. Acesso em: 07/01/2008.

SABBADINI, Francisco Santos; GONCALVES, A. A.; De OLIVEIRA, M. J. F. Gerenciamento de restrições e solução de problemas em emergência hospitalar. Uma abordagem orientada ao paciente. In: XXXI EnAMPAD, 2007, Rio de Janeiro. Anais do XXXI EnAMPAD, 2007. v. 31. 
SANTOS, O. M.; SILVA, P. D. A.; FURTADO, K. G.; COGAN, Samuel. A Teoria das Restrições no Processo de Refino de Petróleo. In: $6^{\circ}$ Congresso USP Controladoria e Contabilidade, 2006, São Paulo. $6^{\circ}$ Congresso USP Controladoria e Contabilidade. São Paulo: FEA - USP, 2006.

TEORIA das Restrições (TOC - Theory of Constraints). Disponível em: http:// www.goldrattgroup.com.br. Acesso em: 08/01/2008.

WATSON, Kevin J.; BLACKSTONE, John H.; GARDINER, Stanley C. The evolution of a management philosophy: The Theory of Constraints. Journal of Operations Management, n. 25, p. 387-402, 2007. 